\title{
Implementation and application of gray fuzzy decision in English teaching quality
}

\author{
Chunyi Lou, Liang Lu, Yan Ding \& Xuena Cui \\ Qinhuangdao Institute of Technology, Qinhuangdao, Hebei, China
}

\begin{abstract}
As a system distinguishing decision, the gray decision can solve most of the issues related to the gray fuzzy multi-criteria decision in real life. This paper establishes a gray fuzzy decision model based the English teaching quality, in order to evaluate the English teaching quality. The model defines the fuzzy set according to the index attributes, and gives the membership for the gray fuzzy relations between indices, and then obtains the weight results of each index based on the calculation of the gray fuzzy. Finally, this paper verifies the availability of the model through the actual teaching examples.
\end{abstract}

Keywords: English teaching quality; gray fuzzy decision; comparison matrix

\section{INTRODUCTION}

English teaching quality is mainly manifested in the objective, systematic, normative, and efficiency and effectiveness principle of English teaching quality. A better teaching quality comes from joint action of each component. Each link of teaching shall be organized rationally, in order to form a good teaching quality assurance system. In the gray fuzzy decision model, the weight definition of AHP mainly includes: establishment of the hierarchical structure, construction of the judgment matrix and calculation of the relative weight, as well as calculation of the synthetic right of the attribute target. The weight definition can be used to obtain the evaluation results of better English teaching quality under a number of factors of the students, teachers, schools and so on.

\section{ESTABLISHMENT OF GRAY FUZZY DECISION MODEL}

Supposing that the target has $n$ attributes $\left(u_{1}, u_{2}, u_{3}, \ldots, u_{n}\right)$, under the criterion $C$, two different attributes of $u_{i}$ and $u_{i}$ are compared. The importance degree of $u_{i}$ and $u_{j}$ are denoted by $u_{i j}$ and $u_{j i}$ under the criterion $C$. Where, $u_{i j}$ and $u_{j i}$ satisfy:

$u_{i j} \geq 0, \quad u_{j i} \geq 0, u_{i j} \cdot u_{j i}=1$
However, the comparison of $u_{i}$ itself is meaningless. Setting that $u_{i i}=0(1 \leq i \leq n)$.

For the definition of the comparison with $u_{i j}$ and $u_{j i}$ : if $u_{i j}>u_{j i}$, then $u_{i}$ is more important than $u_{j}$.

Consistency analysis:

The judgment matrix of the attributes has a necessary and sufficient condition of consistency, for any $i$

$$
g\left(u_{i k}\right)-g\left[\sum_{j \in I_{i}} g\left(u_{j k}\right)\right] \geq 0 \quad, 1 \leq k \leq n
$$

Assuming that

$$
W_{c}(i)=\frac{2}{n(n-1)} \sum_{j=1}^{n} u_{i j}
$$

$W_{c}=\left[W_{c}(1), W_{c}(2), \ldots, W_{c}(n),\right]^{T}$ is defined as the relative weight. The comparison matrix can be expressed as:

$$
\begin{aligned}
& \begin{array}{lllll|l}
C & u_{1} & u_{2} & \cdots & u_{n} & W_{c}
\end{array}
\end{aligned}
$$

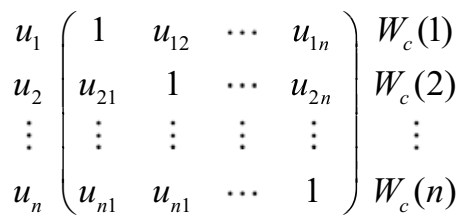


3 VERIFICATION OF NUMBERICAL EXAMPLES - ANALYSIS OF ENGLISH TEACHING QUALITY

Target layer: analysis of English teaching quality Criterion layer: $c_{1}$ is the objective principle; $c_{2}$ is the systematic principle; $c_{3}$ is the normative principle; $c_{4}$ is the principle of efficiency and effectiveness.

Result layer: $A_{1}$ is the students themselves; $A_{2}$ is the teaching materials and instructional design; $A_{3}$ is the teacher factor.

The hierarchical analysis system of the criterion layer is shown in Table 1.

Table 1. Hierarchical analysis system of the criterion layer

\begin{tabular}{ll}
\hline Target layer & Criterion layer \\
\hline & Objective principle \\
Decision analysis of English & Systematic principle \\
teaching quality & Normative principle \\
& $\begin{array}{c}\text { Efficiency and effectiveness } \\
\text { principle }\end{array}$ \\
\hline
\end{tabular}

It corresponds to the index in each result layer. The hierarchical structure is established, as shown in Figure 1.

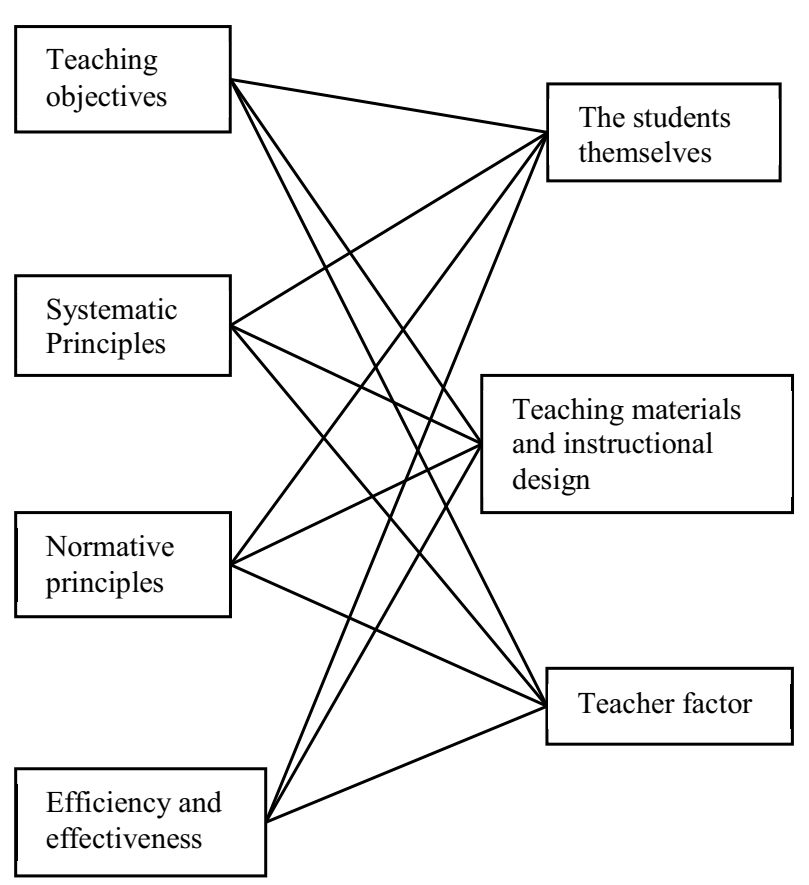

Figure 1. Second hierarchical structural diagram

\subsection{Construction of the judgment matrix at each layer}

The proportion of each criterion target at the criterion layer is different. Through the research of the criterion layer by the researchers, and according to the numbers from 1 to 9 and their reciprocal values, the proportion of each criterion target can be determined. This paper carries out the weight analysis based on the scale table of 1 to 9 shown in Table 2.
Table 2. Scale table of 1 to 9

\begin{tabular}{ll}
\hline Scale $a_{i j}$ & Definition \\
\hline 1 & i factor is equally important to $\mathrm{j}$ factor \\
3 & i factor is slightly important than $\mathrm{j}$ factor \\
5 & i factor is more important than $\mathrm{j}$ factor \\
7 & i factor and $\mathrm{j}$ factor are very important \\
9 & i factor and $\mathrm{j}$ factor are absolutely important \\
$2,4,6,8$ & $\begin{array}{l}\text { Scale values corresponding to the intermediate } \\
\text { state in above judgment }\end{array}$ \\
Reciprocal & If $\mathrm{i}$ factor is weaker than $\mathrm{j}$ factor, the judgment \\
& value is a reciprocal \\
\hline
\end{tabular}

First, the judgment matrix is solved. Based on the above principle, referring to the scale setting from 1 to 9 , according to the experience of the experts and the author, and referring to a lot of literatures, the pairwise comparison matrices can be obtained, as shown in the following matrix.

Where, the comparison matrix $A$ is the comparison matrix between the target layer and the criterion layer. The comparison matrix $c_{1}-c_{4}$ is the comparison matrix between the criterion layer and scheme layer. In the criterion layer, there are comparison matrices of the objective principle, systematic principle, normative principle, and efficiency and effectiveness principle.

$A=\left(\begin{array}{cccc}1 & 1 / 3 & 3 & 3 \\ 3 & 1 & 5 & 7 \\ 1 / 3 & 1 / 5 & 1 & 1 / 3 \\ 1 / 3 & 1 / 7 & 3 & 1\end{array}\right)$

Comparison matrix of objective principle of English teaching quality:

$c_{1}=\left(\begin{array}{ccc}1 & 7 & 7 \\ 1 / 7 & 1 & 5 \\ 1 / 7 & 1 / 5 & 1\end{array}\right)$

Comparison matrix of systematic principle of English teaching quality:

$c_{2}=\left(\begin{array}{ccc}1 & 8 & 7 \\ 1 / 8 & 1 & 5 \\ 1 / 7 & 1 / 5 & 1\end{array}\right)$

Comparison matrix of normative principle of English teaching quality:

$c_{3}=\left(\begin{array}{ccc}1 & 5 & 1 / 3 \\ 1 / 5 & 1 & 7 \\ 3 & 1 / 7 & 1\end{array}\right)$

Comparison matrix of efficiency and effectiveness principle of English teaching quality:

$c_{4}=\left(\begin{array}{ccc}1 & 5 & 1 / 3 \\ 1 / 5 & 1 & 1 / 9 \\ 3 & 9 & 1\end{array}\right)$ 


\subsection{Single level sorting and consistency test}

The consistence index can be used to test the above comparison matrices:

$C I=\frac{\lambda_{\max }-n}{n-1}$

Where: $\lambda_{\max }$ is the maximum eigenvalue; $n$ is the order of the comparison matrix; the smaller the value of $C I$ is, the closer to consistency the judgment matrix is. The greater the value of $C I$ is, the lower the known degree is.

\subsection{Total level sorting and consistency test}

$$
A=\left\{\begin{array}{cccc}
1 & 1 / 3 & 3 & 3 \\
3 & 1 & 5 & 5 \\
1 / 3 & 1 / 5 & 1 & 1 \\
1 / 3 & 1 / 5 & 1 & 1
\end{array}\right\}
$$

Through normalization of the column vector of the matrix $A$,

$$
A^{\prime}=\left\{\begin{array}{llll}
0.214 & 0.192 & 0.3 & 0.3 \\
0.075 & 0.577 & 0.5 & 0.5 \\
0.121 & 0.115 & 0.1 & 0.1 \\
0.201 & 0.115 & 0.1 & 0.1
\end{array}\right\}
$$

Summation of the column vector:

$$
A^{\prime \prime}=\left(\begin{array}{llll}
1.066 & 2.22 & 0.386 & 0.386
\end{array}\right)
$$

Through normalization:

$$
W^{(0)}=\left(\begin{array}{llll}
0.25 & 0.56 & 0.097 & 0.07
\end{array}\right)^{T}
$$

Obtain:

$$
A^{\prime \prime} W^{(0)}=\left\{\begin{array}{cccc}
1 & 1 / 3 & 3 & 3 \\
3 & 1 & 5 & 5 \\
1 / 3 & 1 / 5 & 1 & 1 \\
1 / 3 & 1 / 5 & 1 & 1
\end{array}\right\}\left\{\begin{array}{c}
0.2514 \\
0.555 \\
0.0965 \\
0.0965
\end{array}\right\}=\left\{\begin{array}{l}
1.012 \\
2.275 \\
0.387 \\
0.387
\end{array}\right\}
$$$$
\lambda_{\max }^{(0)}=\frac{1}{4}\left(\frac{1.054}{0.257}+\frac{2.254}{0.786}+\frac{0.257}{0.045}+\frac{0.457}{0.078}\right)=4.038
$$

$$
w^{(0)}=\left(\begin{array}{c}
0.278 \\
0.56 \\
0.045 \\
0.098
\end{array}\right)
$$

In the process of solving the matrix $A$, similarly, the comparison matrices of the objective principle, sys- tematic principle, normative principle, and efficiency and effectiveness principle of English teaching quality are as follows:

$B_{1}=\left\{\begin{array}{ccc}1 & 1 & 1 / 3 \\ 2 & 1 & 1 / 3 \\ 3 & 6 & 1\end{array}\right\}, \quad B_{2}=\left\{\begin{array}{ccc}1 & 5 & 5 \\ 1 / 5 & 1 & 2 \\ 1 / 5 & 1 / 5 & 1\end{array}\right\}$

$B_{3}=\left\{\begin{array}{ccc}1 & 6 & 8 \\ 1 / 5 & 1 & 5 \\ 1 / 8 & 1 / 5 & 1\end{array}\right\}, \quad B_{4}=\left\{\begin{array}{ccc}1 & 8 & 8 \\ 1 / 5 & 1 & 5 \\ 1 / 8 & 1 / 5 & 1\end{array}\right\}$

Thus, the eigenvalues and eigenvectors of the objective principle, systematic principle, normative principle, and efficiency and effectiveness principle of English teaching quality are as follows:

$\lambda_{\max }^{(1)}=3.31, \omega^{(1)}{ }_{1}=\left\{\begin{array}{c}0.252 \\ 0.089 \\ 0.66\end{array}\right\}$

$\lambda_{\text {max }}^{(2)}=3.12, \omega_{2}^{(1)}=\left\{\begin{array}{l}0.575 \\ 0.286 \\ 0.139\end{array}\right\}$

$\lambda_{\text {max }}^{(3)}=3.30, \omega_{3}^{(1)}=\left\{\begin{array}{l}0.624 \\ 0.240 \\ 0.136\end{array}\right\}$

$\lambda_{\max }^{(4)}=4.05, \omega^{(1)}{ }_{4}=\left\{\begin{array}{l}0.185 \\ 0.240 \\ 0.575\end{array}\right\}$

The consistence index can be used to test the rationality of the weight value:

$C I=\frac{\lambda_{\max }-n}{n-1}, \quad C R=\frac{C I}{R I}$

RI is shown in Table 3.

Table 3. RI values

\begin{tabular}{llllllllllll}
\hline $\mathrm{n}$ & 1 & 2 & 3 & 4 & 5 & 6 & 7 & 8 & 9 & 10 & 11 \\
\hline RI & 0 & 0 & 0.58 & 0.90 & 1.12 & 1.24 & 1.32 & 1.41 & 1.45 & 1.49 & 1.51 \\
\hline
\end{tabular}

According to the judgment matrix $A, \lambda^{(0)}{ }_{\text {max }}=4.073$. Corresponding to Table 7, $R I=0.9$.

$C I=\frac{4.073-4}{4-1}=0.24$

$C R=\frac{C I}{R I}=\frac{0.024}{0.90}=0.027<0.1$ 
The result is less than 0.1 , indicating that the result of the consistency test of $A$ is rational, and it moves within the permissible range, then the eigenvector obtained by solving the matrix $A$ can be described as a weight vector.

(2) Similarly, the consistency test is done for the judgment matrices, $B_{1}, B_{2}, B_{3}$ and $B_{4}$, obtaining the weight vector. The calculation results from the target layer to the scheme layer are as follows.

Comparison matrix of objective principle of English teaching quality:

$$
\omega_{1}^{(1)}=\left(\begin{array}{lll}
0.624 & 0.234 & 0.136
\end{array}\right)^{\mathrm{T}}
$$

Systematic principle of English teaching quality:

$\omega_{2}^{(2)}=\left(\begin{array}{lll}0.185 & 0.24 & 0.575\end{array}\right)^{\mathrm{T}}$

Normative principle of English teaching quality:

$\omega_{3}^{(3)}=\left(\begin{array}{lll}0.252 & 0.089 & 0.66\end{array}\right)^{\mathrm{T}}$

Efficiency and effectiveness principle of English teaching quality:

$\omega_{4}^{(4)}=\left(\begin{array}{lll}0.575 & 0.286 & 0.139\end{array}\right)^{\mathrm{T}}$

Computing structure is as follows:

$$
\begin{aligned}
\omega^{(1)} & =\left(\omega_{1}^{(1)}, \omega_{2}^{(1)}, \omega_{3}^{(1)}, \omega_{3}^{(1)}\right) \\
& =\left\{\begin{array}{cccc}
0.624 & 0.185 & 0.252 & 0.575 \\
0.234 & 0.240 & 0.089 & 0.286 \\
0.136 & 0.575 & 0.66 & 0.139
\end{array}\right\}
\end{aligned}
$$

The decision result:

$$
w=w^{(1)} w^{(0)}=\left\{\begin{array}{l}
0.37 \\
0.30 \\
0.33
\end{array}\right\}
$$

Result: based on the result of the gray fuzzy weight, this paper obtains that the proportion of the students themselves is $37 \%$, the proportion of the teaching materials and instructional design $\left(A_{2}\right)$ is $30 \%$, and the promotion of the teacher factor $\left(A_{3}\right)$ is $33 \%$.

\section{CONCLUSION}

This paper analyzes the proportion of the students themselves, teaching materials and instructional design, and teacher factor based on the gray fuzzy model, and also analyzes that the weight value is more balanced. In other words, the improvement of English teaching quality requires joint effort of these three aspects. However, as educated students, their own learning attitude, practice planning and learning ability are an important decision-making power. Therefore, the improvement of English teaching quality requires joint efforts of the students themselves, teaching resources in school, teachers and many other aspects.

\section{REFERENCE}

[1] Chen Yuhun, Dai Ruihua, Yang Xiaojiang, et al. 2004. Introduction to Higher Education Quality Guarantee System. Beijing: Beijing Normal University Press.

[2] Xiao Xinping, Song Zhongmin, Li Feng. 2005. Gray Technological Base and Application. Beijing: Science Press, pp.9-20.

[3] Zhang Wenzhong. 2005. Analysis of domestic research analysis of foreign language learning motivation. Foreign Language World, (4).

[4] Niu Guixia. 2006. Research on college English classroom teaching quality evaluation system. Education and Occupation, 8.

[5] Wu Shunxiang. 2006. Applied Research on the Rough Set and Gray System Theory. Xiamen: Xiamen Science.

[6] Xu Qiuqin, Ren Weili. 2005. Analysis of college English teaching reform. China Higher Education Research, 5.

[7] Bi Fengchun. 2007. Discussion of improvement of college English teaching quality. Journal of Liaoning Administration College, (04).

[8] Zhang Weihua. 2004. Discussion of multi-index comprehensive evaluation quality. Statistics and Decision, (12): $126-127$. 